\title{
Reform of Teaching Mode of Mechanical CAD/CAM Comprehensive Practice
}

\section{Tong Dong}

Department of Mechanical Engineering, Dalian Vocational \& Technical College, Dalian, 116037, China

dt8056@163.com

Keywords: Quality test, parameter optimization, teaching mode

Abstract. The traditional teaching mode of mechanical CAD/CAM comprehensive practice only pay attention to training operating ability of software, ignore training the ability of using the software to solving practical problems in manufacture. In the light of using the software to solving practical problems in manufacture, training applied skilled personnel, reform of teaching mode is carried out, which includes design, manufacture, test, process parameters optimization. It could strengthen the students' comprehensive ability of using CAD/CAM, it may be with guiding significance to training reform of higher vocational colleges.

\section{Introduction}

$\mathrm{CAD} / \mathrm{CAM}$ is one of the important courses in higher vocational colleges, which includes computer graphics, CAD, CAE, CAPP, CAM etc. Now, teaching method of the CAD/CAM course is not right, which can't satisfy the company's requirement. So curriculum revolution is needed, in especial, reform of teaching mode of mechanical CAD/CAM comprehensive practice.

\section{Reform idea of Teaching Mode of Mechanical CAD/CAM Comprehensive Practice}

At present, the course of mechanical CAD/CAM is popular in higher vocational colleges, teaching mode of practice mainly includes modeling by CAD module, setting up process by CAM module, optimizing process parameters on the basis of simulation, finally getting the NC program. The traditional teaching mode of mechanical CAD/CAM comprehensive practice only pay attention to training operating ability of software, ignore training the ability of using the software to solving practical problems in manufacture. Simulation is a ideal state, more complicate factors can influence the working accuracy in manufacture [1]. So, in the process of mechanical CAD/CAM comprehensive practice, machining is needed to test the NC program, after that, process parameters can be optimized according to the working accuracy. On the basis of the probelm, a perfect teaching mode of mechanical CAD/CAM comprehensive practice is carried out, as shown in Figure 1.

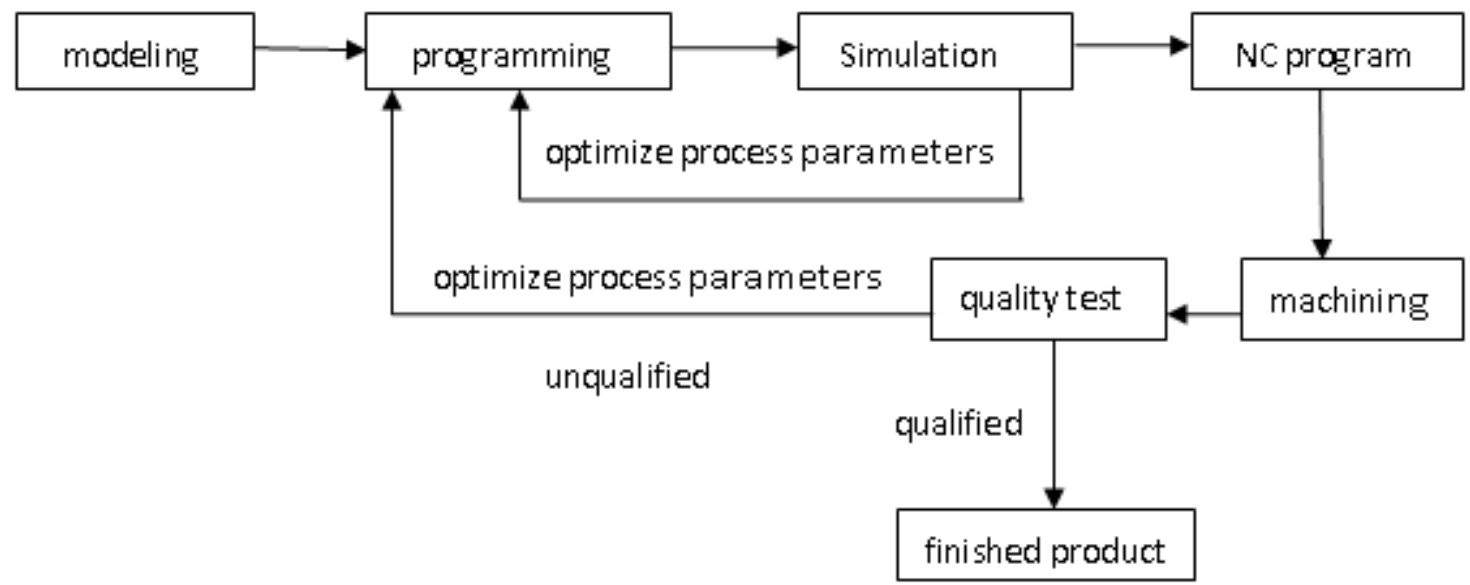

Fig. 1 teaching mode of mechanical CAD/CAM comprehensive practice 


\section{Application of the Teaching Mode}

Parametric Modeling. Completing modeling automatically according to the given parameters is called parametric design [2]. At present, most of the softwares can realize parametric modeling. Simple model can be finished by dimension - driven, complex model can be finished by programming. The students finish modeling of the impellor by UG NX10.0, as shown in Figure 2. This practice is to strengthen the students' ability of parametric modeling. The task - driven approach is used in teaching, the students first finish the model to prepare for programming.

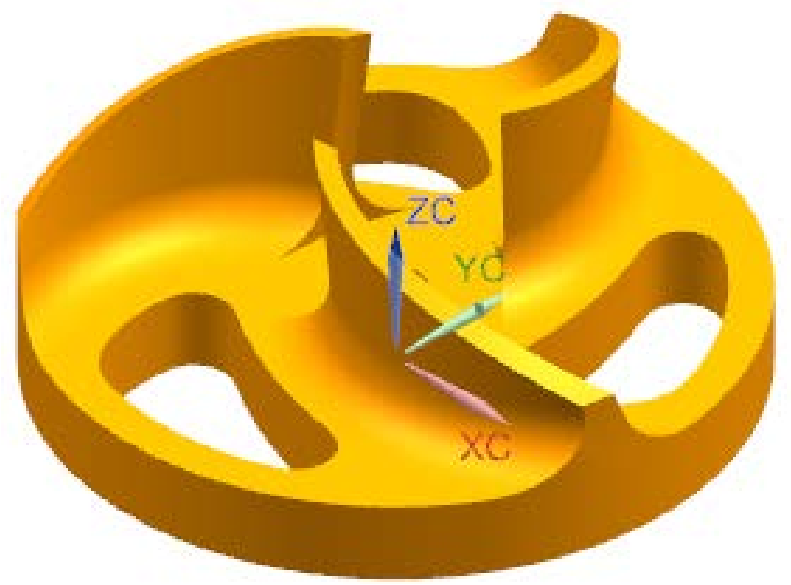

Fig. 2 impellor model

Programming. To reach the expectant machining effect, a program of high quality is needed [3]. Programming of complex model can't be finished by hand, the CAM software can work well. The software can create tool path by the process engineering, tools, knife way, cutting method, cut-in and cut-out, cutting parameters given by handler. The tool path created by UG NX is shown in Figure 3. Before making the NC program, the software can simulate the machining, then compare with the model, as shown in Figure 4. After simulation, the machining parameters can be optimized. The practice can strength the students' ability of programming by software.

Machining. After inputting the NC program to numerical control machine, the handler only need inputting the tool parameters, then, the machine can working according to the NC program [4-5]. In the progress, the students can advance the ability of holding machines. The students can not only study some knowledge of machine, but also know well some skill of machining. The comprehensive ability of machining can be trained.

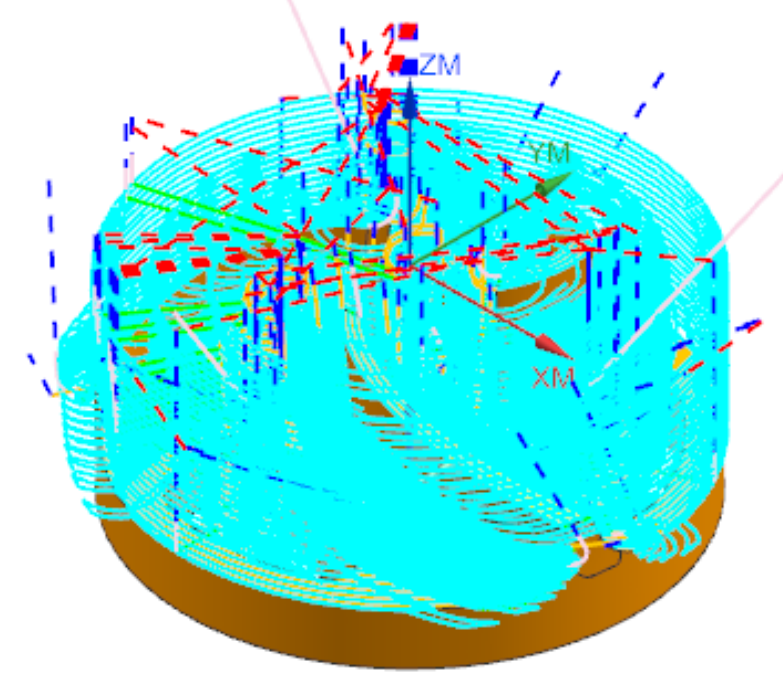

Fig. 3 tool path 


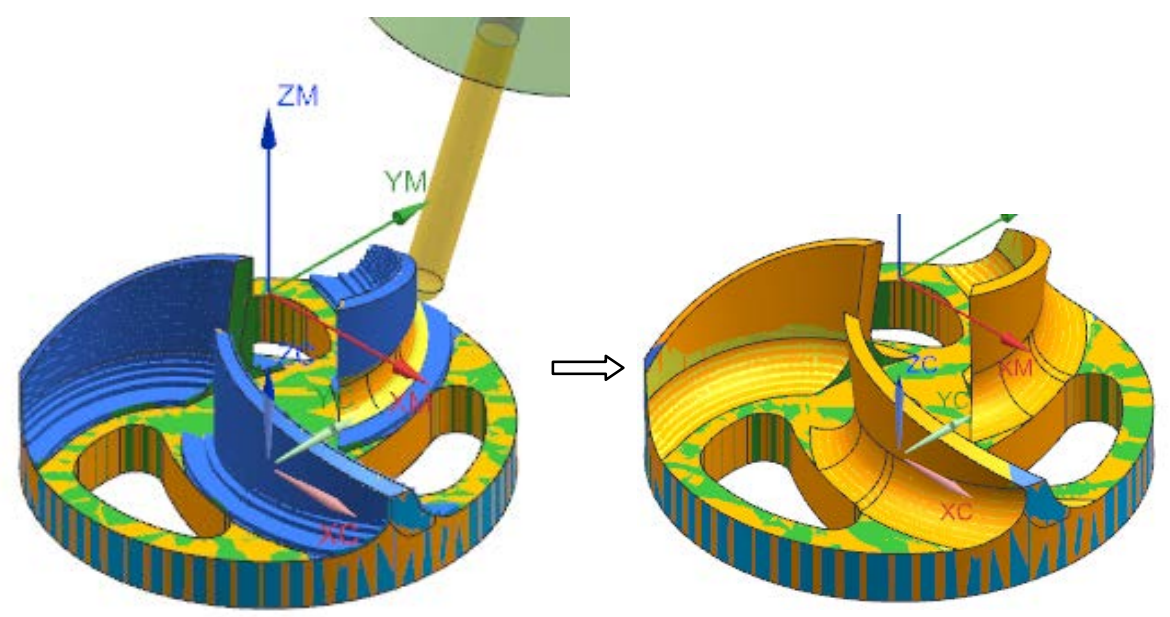

Fig. 4 simulate the machining

Quality Test. After gathering three-dimensional data of workpiece by scanner (as shown in Figure 5), use Geomagic Wrap software to handle point cloud, and get complete point cloud (as shown in Figure 6). Then use Geomagic Control software to compare point cloud with original CAD model, accordingly get test result, as shown in Figure 7, which can show machining error [6-8]. If the machining error is unqualified, the students can analyze the reason, then adjust the machining parameters to get the optimized NC program. This practice can advance the student's ability of solving practical problems in manufacture.

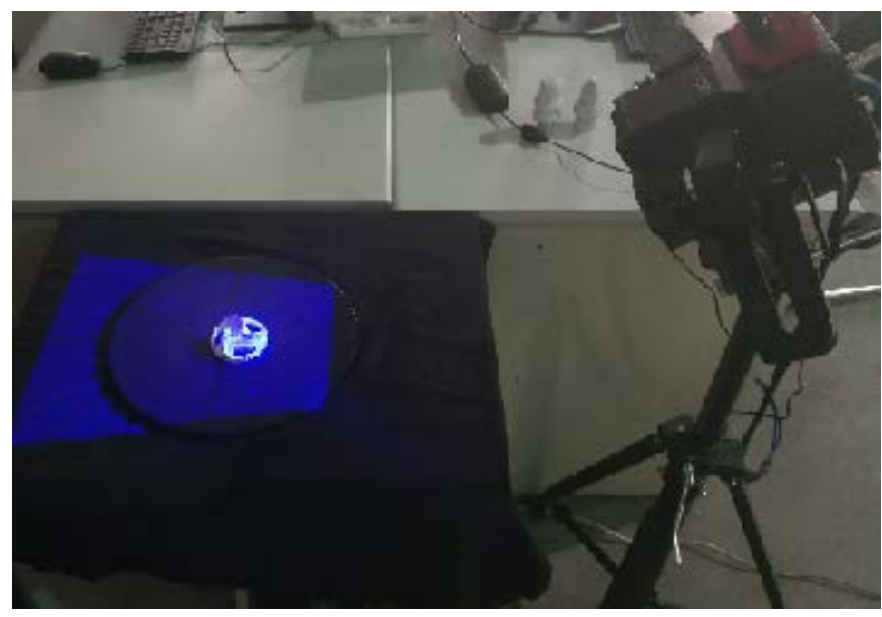

Fig. 5 data acquisition

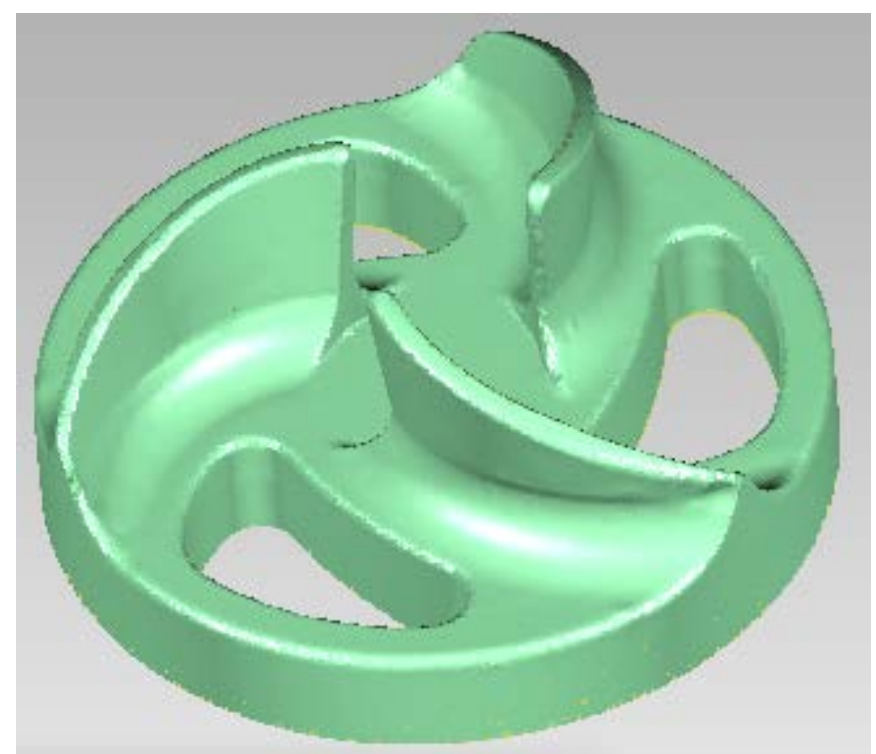

Fig. 6 point cloud 


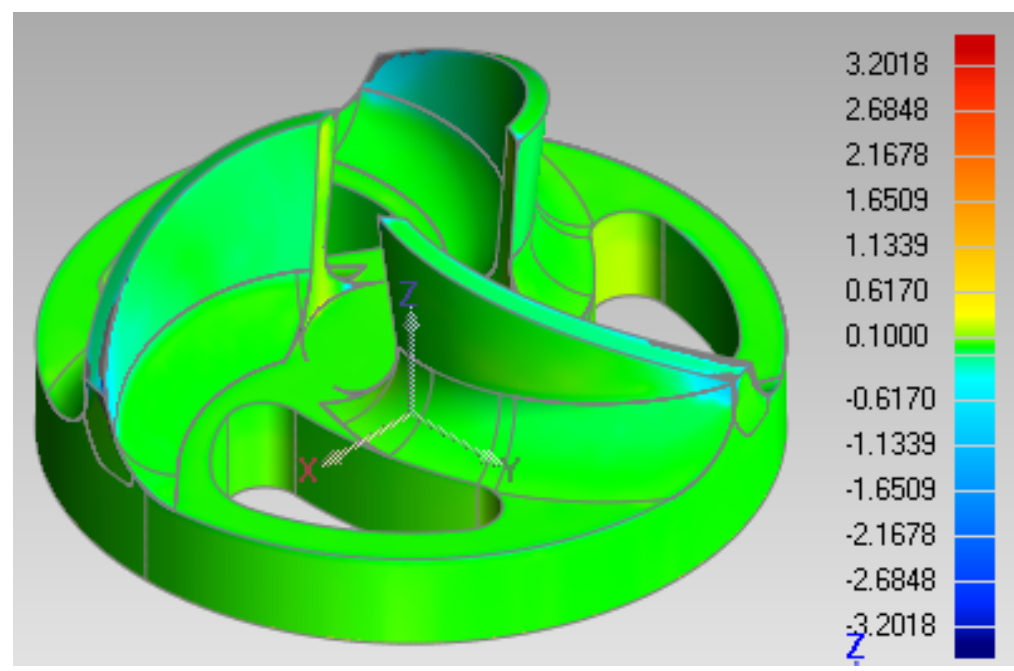

Fig. 7 test result

\section{Conclusion}

Now, the course of mechanical CAD/CAM is an important course in most of the higher vocational colleges, the teaching mode of mechanical CAD/CAM comprehensive practice carried out in the paper give a new thinking for tractical training. The teaching mode give the student a chance to solving practical problems in manufacture, which can satisfy the company’s requirement.

\section{References}

[1] Zheng-hong Zhu, Chun-wei Zhang. The Factors Influencing the Machining Accuracy [J]. Modular Machine Tool \& Automatic Manufacturing Technique, 2008(11):76-85.

[2] Xiao-hong Tang, Ling-zhi Zhou. NURBS Modeling and Parametric Design for Helical Rotors [J]. Journal of Central South University of Forestry \& Technology, 2009, 29(3):121-124.

[3] ZHAO Yu. Design of technical parameter in its model CAM program [J]. Journal of Liaoning Technical University(Natural Science), 2008,27(5):254-256.

[4] Xin-qiang Yang. Application of Master CAM Software in NC Lathe Machining[J]. Die \& Mould Manufacture, 2008(5):18-24.

[5]Jie-chun Yan. Research on the mulit-axis CNC programming and processing simulation based on UG and Vericut software[J].Manufacturing Automation,2012,34(2):41-43.

[6] Li-juan Li, Shan Gao, Xue-zhu Lin. Workpiece deviation detection techniques based on geomagic qualify[J]. Manufacturing Automation, 2014,36(5):35-38.

[7] Guo-chao Liu, Hui Liang. Application of Three-dimensional Laser Scanning Technology in Detecting Surface Machining Quality of Special-shaped Products [J]. Site Investigation Science and Technology, 2015.

[8] Xue-rong Yang, Si-yuan Chen, Zhong-ning Guo. Reform and practice of technological teaching in reverse engineering based on autonomous project-driven[J].Experimental Technology and Management,2016,33(1):179-182. 